\title{
Increased brain uptake and oxidation of acetate in heavy drinkers
}

\author{
Lihong Jiang, ${ }^{1}$ Barbara Irene Gulanski, ${ }^{2}$ Henk M. De Feyter, ${ }^{1}$ Stuart A. Weinzimer, ${ }^{3}$ \\ Brian Pittman, ${ }^{4}$ Elizabeth Guidone, ${ }^{4}$ Julia Koretski, ${ }^{4}$ Susan Harman, ${ }^{2}$ \\ Ismene L. Petrakis, ${ }^{4}$ John H. Krystal, ${ }^{4}$ and Graeme F. Mason ${ }^{1,4}$
}

${ }^{1}$ Department of Diagnostic Radiology, ${ }^{2}$ Department of Internal Medicine, ${ }^{3}$ Department of Pediatrics, and ${ }^{4}$ Department of Psychiatry, Yale University, School of Medicine, New Haven, Connecticut, USA.

\begin{abstract}
When a person consumes ethanol, the body quickly begins to convert it to acetic acid, which circulates in the blood and can serve as a source of energy for the brain and other organs. This study used ${ }^{13} \mathrm{C}$ magnetic resonance spectroscopy to test whether chronic heavy drinking is associated with greater brain uptake and oxidation of acetic acid, providing a potential metabolic reward or adenosinergic effect as a consequence of drinking. Seven heavy drinkers, who regularly consumed at least 8 drinks per week and at least 4 drinks per day at least once per week, and 7 light drinkers, who consumed fewer than 2 drinks per week were recruited. The subjects were administered $\left[2-{ }^{13} \mathrm{C}\right]$ acetate for 2 hours and scanned throughout that time with magnetic resonance spectroscopy of the brain to observe natural ${ }^{13} \mathrm{C}$ abundance of $\mathrm{N}$-acetylaspartate (NAA) and the appearance of ${ }^{13} \mathrm{C}$-labeled glutamate, glutamine, and acetate. Heavy drinkers had approximately 2 -fold more brain acetate relative to blood and twice as much labeled glutamate and glutamine. The results show that acetate transport and oxidation are faster in heavy drinkers compared with that in light drinkers. Our finding suggests that a new therapeutic approach to supply acetate during alcohol detoxification may be beneficial.
\end{abstract}

\section{Introduction}

Alcohol is the most used recreational substance and one of the most widely abused drugs in the world. Alcohol use is characterized by CNS intoxication symptoms, impaired brain activity, poor motor coordination, and behavioral changes. The impairments in CNS activities are due to alcohol's effect on synthesis, release, and signaling of neuron transmitters, including glutamate, GABA, and other neuron transmitters (1-3). Alcohol use also affects insulin sensitivity that regulates protein, carbohydrate, and fat metabolism (4). Chronic abuse of alcohol can result in tolerance and physical dependence. Although significant advances in understanding of alcohol's effects have been made over the past decades, the pathogenesis of alcohol use and abuse is not fully understood (5). Understanding the mechanisms that lead to tolerance and dependence may give valuable insight into alcohol addiction and vulnerability and ultimately result in effective therapeutic intervention to facilitate detoxification.

Alcohol is converted to acetate in the periphery, particularly in the liver $(6,7)$, and it is released to the blood (8). Administration of ethanol to humans elevates blood acetate $(6,9,10)$ from $<0.1$ $\mathrm{mM}$ to 1 to $2 \mathrm{mM}$ within minutes of the start of the administration $(11,12)$. Consumption of enough alcohol to achieve breath alcohol levels of even $50 \mathrm{mg} \%$ is sufficient for plasma acetate levels to approach 1-2 mM, beyond which the plasma acetate concentration does not rise $(6,9,10,12,13)$. Acetate travels to other organs, including the brain, for use as an energy substrate (14) and in fatty acid and cholesterol biosynthesis $(15,16)$. The conversion of ethanol to acetate begins with metabolism to acetaldehyde. In people who consume alcohol at moderate levels or occasionally, the ethanol is metabolized to acetaldehyde in a reversible reaction catalyzed

Conflict of interest: John H. Krystal has a research grant from Pfizer and receives compensation from Society of Biological Psychiatry as its editor. Barbara Irene Gulanski holds common stock in Pfizer.

Citation for this article: J Clin Invest. 2013;123(4):1605-1614. doi:10.1172/JCI65153 by alcohol dehydrogenase in cytosol, and subsequently acetaldehyde is oxidized to acetate in an irreversible reaction by aldehyde dehydrogenase in mitochondria (5). In people who are chronic and heavy alcohol consumers, a second pathway becomes prominent, and that is the microsomal ethanol-oxidizing system, which functions in the smooth endoplasmic reticulum of hepatocytes to convert ethanol to acetaldehyde via cytochrome P450. A third route of ethanol metabolism is through catalase, which is located in cell bodies and is capable of oxidizing small amounts of ethanol to acetaldehyde. Acetaldehyde dehydrogenase quickly catalyzes the conversion of acetaldehyde to acetate, and alcohol-dependent individuals show elevated acetate up to 24 hours after the last drink (17). Acetate enters the tricarboxylic acid (TCA) cycle for oxidation via acetyl-CoA synthetase, and the process of oxidation generates adenosine (18-21), which has sedating properties similar to those of ethanol (22-24). One may expect heavy drinkers to have long periods of time with elevated levels of adenosine in their tissues.

In brain, glucose is the major supply of mitochondrial energy oxidation; however, acetate can also be used as an alternative energy source, and it is almost exclusively used by astrocytes (25). Heavy alcohol drinking has been reported to lead to hypoglycemia (26). Previously, studies on acetate metabolism of patients with diabetes who had previous recurrent hypoglycemia and healthy rats that underwent 3 days of antecedent recurrent hypoglycemia showed increased brain acetate transport and oxidation $(27,28)$. Although acetate metabolism has been characterized in situations other than drinking, links between acetate metabolism and alcohol consumption are not clear. Recent data show that alcohol decreases brain glucose utilization (29-31) and increases acetate uptake (30). These findings lead to our hypothesis: upon chronic heavy alcohol intake, brain can use more acetate as a source of energy. The ethanol-based elevation of blood acetate persists for up to 24 hours (32), so heavy drinkers are exposed to high levels of acetate for long periods of times, and dependent drinkers likely 
A

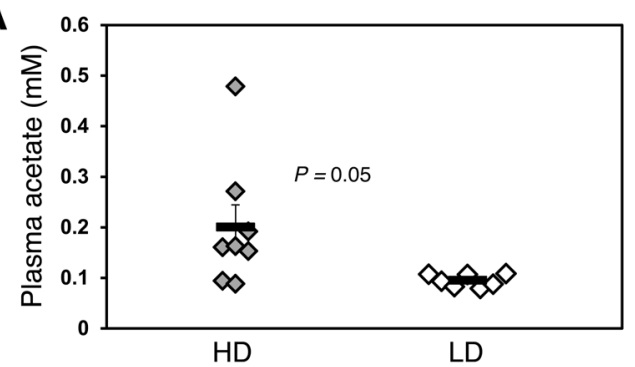

C

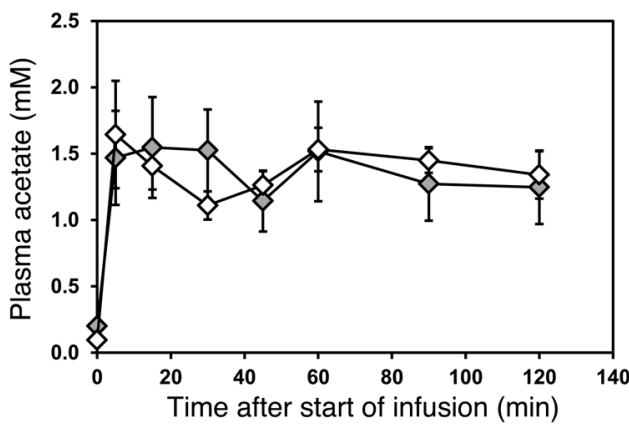

B

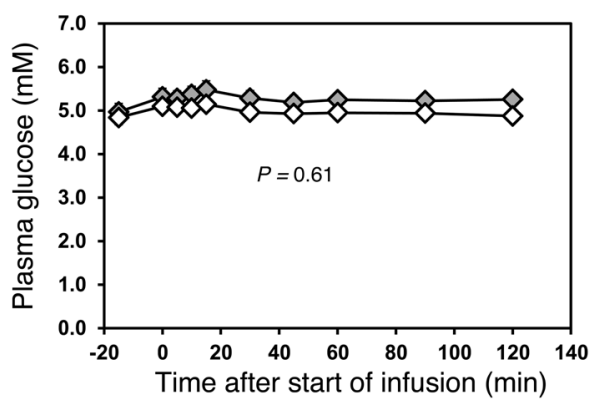

D

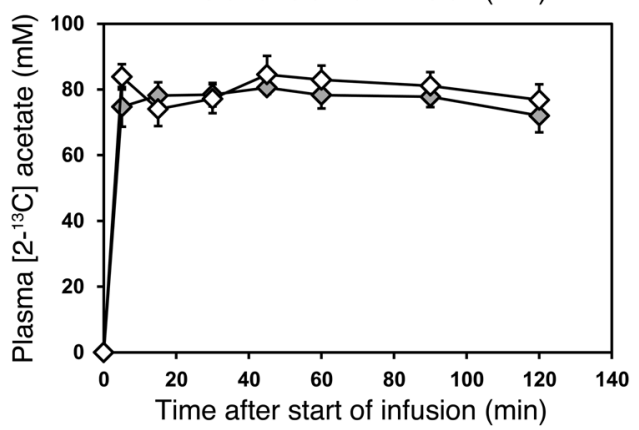

Figure 1

Plasma acetate and glucose concentrations during $\left[2-{ }^{13} \mathrm{C}\right]$ acetate infusion. (A) Plasma acetate concentrations before infusion. Symbols represent individual concentrations; horizontal bars indicate the mean. (B) Averaged plasma glucose concentrations during acetate infusion. (C) Averaged plasma acetate concentrations during [2-13C]acetate infusion. (D) Averaged plasma acetate ${ }^{13} \mathrm{C}$ enrichments during the acetate infusion. Gray diamonds represent heavy drinkers (HD), and white diamonds represent light drinkers (LD). Values with error bars represent mean \pm SEM.

always have elevated acetate. If acetate consumption by brain is higher, then adenosine effects can be expected to be enhanced. Faced with persistent elevation of adenosine, the brain likely adapts, and during withdrawal, the loss of adenosine may contribute to symptoms.

Our goal in this study was to test whether chronic heavy drinking can affect brain acetate uptake and metabolism. To this end, we used $\left[2-{ }^{13} \mathrm{C}\right]$ acetate as a metabolic substrate in combination with in vivo magnetic resonance spectroscopy (MRS) to compare brain acetate consumption in heavy drinkers and light drinkers.

\section{Results}

Impact of heavy drinking on plasma acetate. On a typical drinking day, the heavy drinkers consumed $8 \pm 1$ drinks $(n=7)$, and the light drinkers consumed 1 or 0 (i.e., some drank very rarely). For the heavy drinkers, the last drink was $3 \pm 1$ days earlier $(n=5,2$ did not answer that question), while for the light drinkers, one had a drink 7 days before, and the others consumed no alcohol for at least 20 days and in several cases over 2 months. Heavy drinkers tested sober, with breath alcohol of 0 on the test days, having drunk no fewer than 2 days before the study, and in one case one week before the study. The averaged longest interval without drinking for heavy drinkers was $5 \pm 1$ days. Heavy drinkers had significantly greater levels of plasma acetate before infusion $(0.20 \pm 0.13 \mathrm{mM}$, range: $0.09-0.48 \mathrm{mM})$ compared with those of light drinkers $(0.09 \pm 0.01 \mathrm{mM}$, range: $0.08-0.11 \mathrm{mM})(P=0.05)$ (Figure 1A). Differences in acetate before infusion between the groups may reflect slower acetate clearance rates in the heavy drinkers. Plasma glucose showed no significant difference after overnight fasting, with levels before infusion of $5.0 \pm 0.5 \mathrm{mM}$ for heavy drinkers and $4.8 \pm 0.4 \mathrm{mM}$ for light drinkers $(P=0.6)$. Dur- ing the acetate infusion, subjects showed no significant plasma glucose changes (overall group effect, $P=0.61$ ), with variations of less than $2 \%$ (Figure 1B). Plasma lactate and $\beta$-hydroxybutyrate enter the brain by the same monocarboxylic acid transporter as acetate, and so differences could potentially affect acetate entry to the brain by competitive inhibition. $\beta$-Hydroxybutyrate differed insignificantly between the 2 groups at baseline $(0.17 \pm 0.01 \mathrm{mM}$ and $0.21 \pm 0.11 \mathrm{mM}$ for light and heavy drinkers, respectively, $P=0.13)$ and after 120 minutes $(0.09 \pm 0.03 \mathrm{mM}$ and $0.61 \pm 0.42$ $\mathrm{mM}$, respectively, $P=0.27)$. The rise in $\beta$-hydroxybutyrate during the infusion was significant in the heavy drinkers $(P=0.05)$, if no Bonferroni correction is applied to account for the multiple measures in plasma, but not in the light drinkers $(P=0.28)$. However, plasma lactate showed no significant differences between groups before and during the acetate infusion, with lactate levels before infusion of $0.95 \pm 0.13 \mathrm{mM}$ and $0.83 \pm 0.10 \mathrm{mM}$ for light and heavy drinkers, respectively $(P=0.46)$, rising slightly to 1.03 $\pm 0.12 \mathrm{mM}$ and $0.84 \pm 0.12 \mathrm{mM}$, respectively, by the end of the infusion $(P=0.30)$. The rise in lactate was also insignificant for each group $(P=0.93$ and $P=0.56$ for heavy and light drinkers, respectively) or for all data together $(P=0.63)$. Infusion of $\left[2-{ }^{13} \mathrm{C}\right]$ acetate increased the plasma acetate from baseline $(\sim 0.1 \mathrm{mM})$ to approximately 1 to $2 \mathrm{mM}$ within 5 minutes (Figure 1C) among both groups. The steady-state plasma acetate concentrations between heavy drinkers and light drinkers were comparable (1.2 $\pm 0.3 \mathrm{mM}$ for heavy drinkers and $1.3 \pm 0.2 \mathrm{mM}$ for light drinkers, $P=0.78$; Figure $1 \mathrm{C}$ ). Plasma ${ }^{13} \mathrm{C}$-acetate enrichments followed a similar pattern as plasma acetate concentrations, rising from $0 \%$ to $70 \% \sim 80 \%$ within 5 minutes. No significant differences were seen between groups at steady state $(72 \% \pm 5 \%$ for heavy drinkers and $77 \% \pm 5 \%$ for light drinkers, $P=0.5$; Figure $1 \mathrm{D})$. 

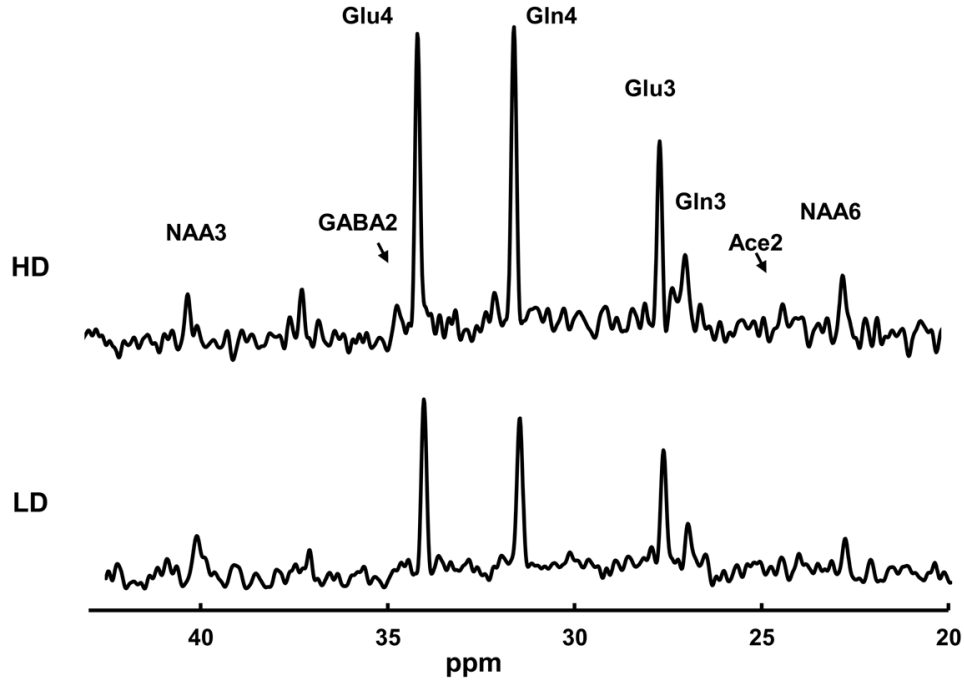

\section{Figure 2}

Steady-state ${ }^{13} \mathrm{C}$-spectra of a heavy drinker (top spectrum) and a light drinker (lower spectrum). The heavy drinker had markedly greater ${ }^{13} \mathrm{C}$ labeling than the light drinker. Acquisition parameters were as follows: 765 complex points; 5,000 $\mathrm{Hz}$ bandwidth; repetition time, 2.5 seconds. A total of 640 acquisitions were grouped to make each spectrum, each representing the final 27 minutes observed while the glutamate and glutamine $\mathrm{C} 4$ labeling were at a steady state. The spectra were zero filled to 16,384 complex points, windowed with $-2 \mathrm{~Hz}$ Lorentzian and $6 \mathrm{~Hz}$ Gaussian broadening, and Fourier transformed.
Impact of heavy drinking on ${ }^{13} \mathrm{C}$ labeling in the brain. Figure 2 shows representative ${ }^{13} \mathrm{C}$-MRS spectra during the steady-state portion of the ${ }^{13} \mathrm{C}$-acetate infusion in a heavy drinkers and light drinkers, normalized to the subjects' own natural ${ }^{13} \mathrm{C}$ abundance of $\mathrm{N}$-acetylaspartate (NAA) $\mathrm{C} 3$ and $\mathrm{C} 6$ resonances. The ${ }^{1} \mathrm{H}$ MRS measurements showed no significant differences between heavy drinkers and light drinkers with respect to any of the metabolites, respectively, including the ratio of NAA to water $(P=0.10)$, that of glutamate to water $(P=0.49)$, that of glutamine to water $(P=0.62)$, and that of GABA to water $(P=0.4)$. The most abundant ${ }^{13} \mathrm{C}$ labeling occurred in the glutamate and glutamine $\mathrm{C} 4$ positions. Heavy drinkers had higher ${ }^{13} \mathrm{C}$ labeling incorporation across the time course in glutamate $\mathrm{C} 4(P=0.01)$ and glutamine $\mathrm{C} 4(P=0.021)$ relative to that of light drinkers, including at the end point ( $P=0.0013$ and 0.012 , respectively) (Figure 3, A and B). Glutamate and glutamine $\mathrm{C} 3$ are also labeled, which occurs as ${ }^{13} \mathrm{C}$ is processed through multiple turns of the TCA cycle.

The time courses of ${ }^{13} \mathrm{C}$ enrichments of glutamate and glutamine $\mathrm{C} 4$ and the steady-state ${ }^{13} \mathrm{C}$ enrichments of glutamate and glutamine $\mathrm{C} 3$ were analyzed with a mathematical model of brain acetate metabolism in CWave software (33) to calculate the metabolic fluxes (Table 1 and Figure 4). Metabolic modeling of the individual time courses showed that heavy drinkers had a greater cerebral metabolic rate of acetate $\left(\mathrm{CMR}_{\mathrm{ac}}\right)$ than light drinkers, with values of $0.069 \pm 0.008 \mathrm{mmol} / \mathrm{min} / \mathrm{kg}$ and $0.048 \pm 0.006 \mathrm{mmol} /$ $\mathrm{min} / \mathrm{kg}$, respectively $(P=0.02)$ (Figure $5 \mathrm{~A}) \cdot{ }^{13} \mathrm{C}$ resonances of GABA, acetate, and other metabolites were small due to their low overall concentrations in the brain. ${ }^{13} \mathrm{C}-\mathrm{GABA}$ was undetectable in light drinkers but was detected at a level of $0.09 \pm 0.03 \mathrm{mmol} /$ $\mathrm{kg}$ in heavy drinkers, indicating that ${ }^{13} \mathrm{C}$-GABA labeling in heavy drinkers is also greater than that in light drinkers (Figure 2). In light drinkers, ${ }^{13} \mathrm{C}$-GABA was necessarily much lower than in heavy drinkers. Some idea of the limit can be drawn from the standard deviation of the spectral noise, $\pm 0.029 \mathrm{mmol} / \mathrm{kg}$. To detect the presence of labeled GABA across the group, signal-to-noise ratios of at least 1.5 would be needed, which have a detection limit of $0.044 \mathrm{mmol} / \mathrm{kg}$. The fraction of glutamate that resides in astroglia (FracGluA) was set to 0.10 , calculated from data in ref. 34 for a similar voxel, but was tested also for a much lower value (0.01),
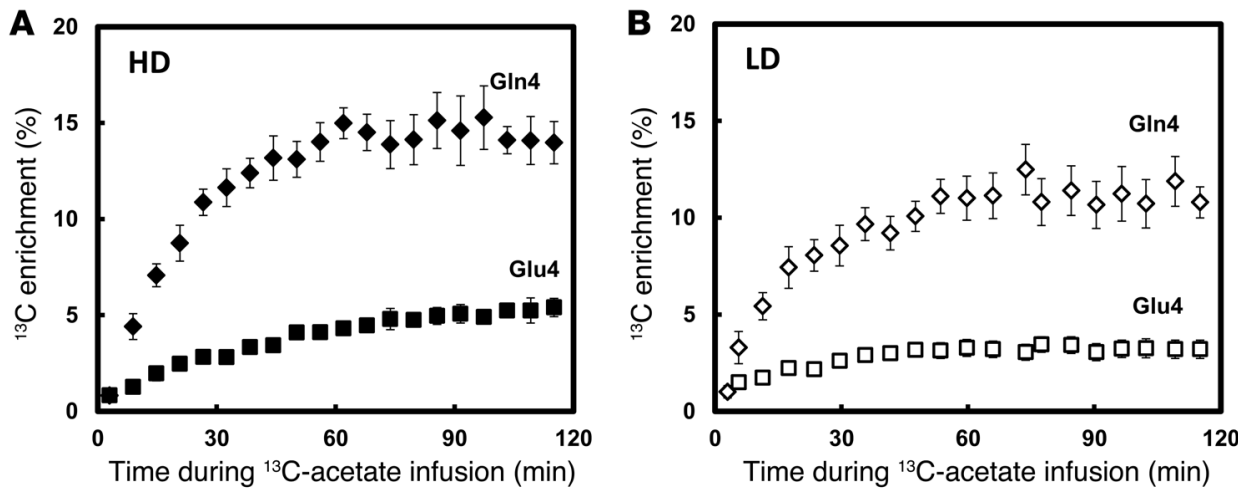

Figure 3

Averaged time courses of the percentage of ${ }^{13} \mathrm{C}$ enrichment of Glu4 and Gln4 for (A) heavy drinkers and (B) light drinkers. Heavy drinkers showed higher ${ }^{13} \mathrm{C}$ labeling in both Glu4 and Gln4, consistent with greater utilization of acetate. Gln4 is represented by black diamonds and Glu4 is represented by black squares in heavy drinkers. Gln4 is represented by white diamonds and Glu4 is represented by white squares in light drinkers. Values with error bars represent group mean \pm SEM. 


\section{Table 1}

Equations used in CWave software to calculate metabolic rates

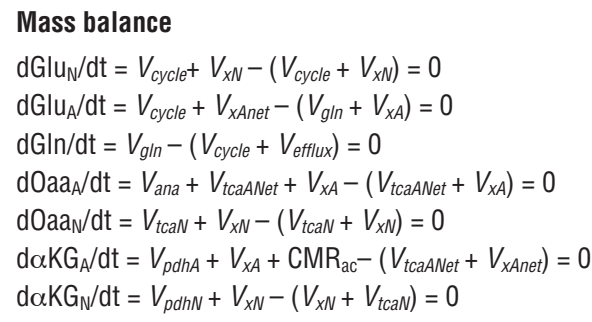

\section{Isotope balance}

$\mathrm{dGl} \mathrm{u}_{\mathrm{N}} / \mathrm{dt}=V_{\text {cycle }}(\mathrm{Gln} / \mathrm{G} / \mathrm{G})+V_{x N}\left(\alpha \mathrm{KG}_{N \mathrm{~N}} / \alpha \mathrm{KG}_{N}\right)-\left(V_{\text {cycle }}+V_{x N}\right)\left(\mathrm{Glu}_{N 4} / \mathrm{Glu}_{N}\right)$

$\mathrm{dGlu} \mathrm{u}_{A} / \mathrm{dt}=V_{\text {cycle }}\left(\mathrm{Glu}_{\mathrm{N} 4} / \mathrm{Glu}_{\mathrm{N}}\right)+V_{x A n e t}\left(\alpha \mathrm{KG}_{\mathrm{AA}} / \alpha \mathrm{KG}_{\mathrm{A}}\right)-\left(V_{\text {gln }}+V_{x A}\right)\left(\mathrm{Glu}_{\mathrm{A} 4} / \mathrm{Glu}_{\mathrm{A}}\right)$

$\mathrm{dGIn} / \mathrm{dt}=V_{\text {gln }}\left(\mathrm{Glu}_{\mathrm{A} A} / \mathrm{Glu}_{\mathrm{A}}\right)-\left(V_{\text {cycle }}+V_{\text {ana }}\right)(\mathrm{Gln} / \mathrm{Gln})$

$\mathrm{dGlu} / \mathrm{d} / \mathrm{dt}=V_{\text {cycle }}\left(\mathrm{Gln}_{3} / \mathrm{Gln}\right)+V_{x N}\left(\alpha \mathrm{KG}_{\mathrm{N} 3} / \alpha \mathrm{KG}_{\mathrm{N}}\right)-\left(V_{c y c l e}+V_{x N}\right)\left(\mathrm{Glu}_{\mathrm{N} 3} / \mathrm{Glu}_{\mathrm{N}}\right)$

$\mathrm{dGIn} / \mathrm{dt}=V_{g l n}\left(\mathrm{Glu}_{\mathrm{A} 3} / \mathrm{Glu}_{\mathrm{A}}\right)-V_{\text {cycle }}\left(\mathrm{Gln} \mathrm{n}_{3} / \mathrm{Gln}\right)$

$d G \mid u_{A 3} / d t=V_{c y c l e}\left(G \mid u_{N 3} / G l u_{N}\right)+V_{X A}\left(\alpha K G_{A 3} / \alpha K G_{A}\right)-\left(V_{g l n}+V_{X A}\right)\left(G \mid u_{A 3} / G u_{A}\right)$

$d \alpha K G_{A 4} / d t=V_{X A}\left(G l_{A A} / G l u_{A}\right)+C M R_{a c}($ acetate $2 /$ acetate $)-\left(V_{t c a A}+V_{x A}\right)\left(\alpha K G_{A 4} / \alpha K G_{A}\right)$

$\mathrm{d} \alpha \mathrm{KG}_{\mathrm{N} 4} / \mathrm{dt}=V_{X N}\left(\mathrm{Glu}_{\mathrm{N}_{4}} / \mathrm{Glu}_{\mathrm{N}}\right)-\left(V_{X N}+V_{\text {tcaN }}\right)\left(\alpha K \mathrm{KG}_{N 4} / \alpha \mathrm{KG}_{N}\right)$

$d \alpha K G_{A 3} / d t=V_{X A}\left(G u_{A 3} / G l u_{A}\right)+V_{t c a A}\left(0 a_{A 3} / 0 a_{A}\right)-\left(V_{t c a A}+V_{X A}\right)\left(\alpha K G_{A 3} / \alpha K G_{A}\right)$

\section{Values of rates}

$\mathrm{CMR}_{\mathrm{ac}}$; cerebral metabolic rate of acetate, iterated

$V_{\text {cycle; }}$, glutamate/glutamine neuron transmitter cycle, calculated as a ratio to $V_{\text {tcaN }}$

based on steady-state Glu and $G \mathrm{n}_{4}$ enrichment $V_{\text {cycle }} / V_{\text {tcaN }}=\left(\operatorname{Glu}_{\mathrm{A4}} /\left(\mathrm{Gln}_{\mathrm{A} 4}-\mathrm{Glu}_{\mathrm{N} 4}\right)(27,71)\right.$

$V_{d}=0.77 \mathrm{ml} / \mathrm{g}$; distribution space of brain water $(72,73)$

$V_{\text {ana }}=0.02 \mu \mathrm{mol} / \mathrm{g} / \mathrm{min}$; anaplerotic flux (74)

$V_{\text {gln }}=V_{\text {cycle }}+V_{\text {ana; }}$ glutamine synthesis rate

$V_{\text {efflux }}=V_{\text {ana; }}$, glutamine efflux, balanced by $V_{\text {ana }}$

$V_{\text {pdhA }}=V_{\text {tcaA }}-\mathrm{CMR}_{\mathrm{ac}}$; astrocytic pyruvate dehydrogenase rate

$V_{\text {pdhN }}=V_{\text {tcan }}=0.73 \mathrm{mmol} / \mathrm{kg} / \mathrm{min}$; neuronal pyruvate dehydrogenase rate equal to neuronal TCA cycle flux set to $0.73 \mathrm{mmol} / \mathrm{kg} / \mathrm{min}$. Because acetate is metabolized

only in astrocytes, there was insufficient sensitivity to calculate $V_{\text {tcan }}(67,75,76)$

$V_{\text {tcaA }}=V_{\text {pdhA }}+\mathrm{CMR}_{\mathrm{ac}} ;$ astrocytic TCA cycle flux, free iterated parameter

$V_{X A}=V_{\text {tcaA }}$ or $10 \times V_{\text {tcaA }}$; astrocytic exchange rate between $\alpha$-ketoglutarate and glutamate

$V_{x N}=10 \times V_{\text {tcan }}$; neuronal exchange rate between $\alpha$-ketoglutarate and glutamate $(66,67)$

\section{Values of pool concentrations}

FracGlu $=0.10$; fraction of total glutamate that resides in astroglia (34)

$\mathrm{Gln}=4.1 \mu \mathrm{mol} / \mathrm{g}$; total brain glutamine concentration (77)

$\mathrm{Glu}=9.1 \mu \mathrm{mol} / \mathrm{g}$; total brain glutamate concentration (77)

$\mathrm{Glu}_{\mathrm{A}}=$ FracGlu$_{\mathrm{A}} \times \mathrm{Glu}_{\text {Total }}$; astrocytic glutamate concentration (78)

$\mathrm{Glu}_{N}=\mathrm{Glu}_{\mathrm{Total}}-\mathrm{Glu}_{\mathrm{A}}$; neuronal glutamate concentration

Oaa $a_{A}$; astrocytic oxaloacetate concentration

Oaan; neuronal oxaloacetate concentration

$\alpha K G_{A} ;$ astrocytic $\alpha$-ketoglutarate concentration

$\alpha K G_{N}$; neuronal $\alpha$-ketoglutarate concentration

$\alpha K G_{A}=\alpha K G_{N}=0 a_{A}=0 A A_{N}=0.1 \mathrm{mmol} / \mathrm{kg}(76)$

$\pm 0.02 \mathrm{mmol} / \mathrm{kg} / \mathrm{min}$ and $0.04 \pm 0.02 \mathrm{mmol} /$ $\mathrm{kg} / \mathrm{min}$ in light and heavy drinkers $(P=0.13)$, and the estimated value of $V_{g l n}$ was $0.22 \pm 0.03$ $\mathrm{mmol} / \mathrm{kg} / \mathrm{min}$ and $0.32 \pm 0.02 \mathrm{mmol} / \mathrm{kg} / \mathrm{min}$ in light and heavy drinkers $(P=0.008)$. It is important to note that lactate from the blood exchanges with lactate that is generated in the brain, and its effect is combined with that of glucose in the rate of flow through pyruvate dehydrogenase.

The metabolic fitting required that the rate of exchange between astrocytic $\alpha$-ketoglutarate and glutamate $\left(V_{x A}\right)$ have an assumed value (Table 1). We fitted the data for Figure 5, A and $B$, with a value of the exchange rate that was 10 -fold greater than the astrocytic TCA cycle rate $\left(V_{t c a A}\right)$. To test the sensitivity of the model to the value of $V_{x A}$, fitting was repeated with $V_{x A}=V_{t c a A}$. The sensitivity test of $V_{x A}$ showed that for the minimum value of $V_{x A}$, which is equal to $V_{t c a A}, \mathrm{CMR}_{\mathrm{ac}}$ was $0.103 \pm 0.013$ $\mathrm{mmol} / \mathrm{kg} / \mathrm{min}$ and $0.061 \pm 0.008 \mathrm{mmol} / \mathrm{kg} /$ min for heavy drinkers and light drinkers, respectively, while for $V_{x A}=10 \times V_{t c a A}, \mathrm{CMR}_{\mathrm{ac}}$ was $0.069 \pm 0.008 \mathrm{mmol} / \mathrm{kg} / \mathrm{min}$ for heavy drinkers and $0.048 \pm 0.006 \mathrm{mmol} / \mathrm{kg} / \mathrm{min}$ for light drinkers. In neither case did the value of $V_{t c a A}$, which was $0.08-0.13 \mathrm{mmol} / \mathrm{kg} /$ min (Figure 5, B and D), differ significantly between heavy drinkers and light drinkers, although in both cases heavy drinkers showed significantly higher $\mathrm{CMR}_{\mathrm{ac}}$ than that of light drinkers $(P=0.02)$ (Figure 5, A and C).

Impact of heavy drinking on brain acetate concentrations. Brain ${ }^{13} \mathrm{C}$-acetate concentrations during the steady-state portion of the infusion of $\left[2-{ }^{13} \mathrm{C}\right]$ acetate were $80 \%$ higher in heavy drinkers $(0.071 \pm 0.014 \mathrm{mmol} / \mathrm{kg})$ than in light drinkers $(0.039 \pm 0.007 \mathrm{mmol} / \mathrm{kg})(P$ $=0.06$; Figure $6 \mathrm{~A}$ ). The ratios of brain $/$ blood ${ }^{13} \mathrm{C}$-acetate concentrations in heavy drinkers were $84 \%$ greater $(0.049 \pm 0.007)$ than those in light drinkers $(0.026 \pm 0.006)(P=0.02$; Figure $6 \mathrm{~B})$. Because brain acetate levels and brain/ blood ratios were higher, while at the same time the brain was consuming more acetate, heavy drinkers must have had elevated bloodbrain transport of acetate compared with that of light drinkers.

Relationship of acetate uptake to recent drinking history. Steady-state glutamate $\mathrm{C} 4{ }^{13} \mathrm{C}$ enrich-

which was found to have a negligible impact on the results. The rate of glutamate-glutamine cycling $\left(V_{\text {cycle }}\right)$ was calculated relative to the neuronal TCA cycle $\left(V_{t c a N}\right)$, using the steady-state enrichments of glutamate and glutamine $\mathrm{C} 4$, as stated in Table 1 . The value of $V_{\text {cycle }}$ was $0.18 \pm 0.03 \mathrm{mmol} / \mathrm{kg} / \mathrm{min}$ and $0.28 \pm 0.02 \mathrm{mmol} /$ $\mathrm{kg} / \mathrm{min}$ in light and heavy drinkers, respectively $(P=0.008)$. Two other parameters, the astroglial rate of pyruvate dehydrogenase $\left(V_{p d h A}\right)$ and the rate of glutamine synthesis $\left(V_{g l n}\right)$, were defined from other rates, as defined in Table 1. $V_{p d h A}$ was estimated to be 0.08 ments were significantly correlated with the number of drinks consumed in the past 30 days $\left(P=0.0005, r^{2}=0.8\right.$; Figure $\left.7 \mathrm{~A}\right)$ and past 60 days $\left(P=0.0006, r^{2}=0.8\right)$. Steady-state glutamine $\mathrm{C} 4{ }^{13} \mathrm{C}$ enrichments were correlated with the number of drinking days in the past month $\left(P=0.03, r^{2}=0.6\right.$; Figure $\left.7 \mathrm{~B}\right)$, although the latter comparison did not survive a Bonferroni correction. The relationship suggests that the increase in the metabolite labeling is an adaptation of the brain to obtain more energy from acetate during chronic heavy drinking. 


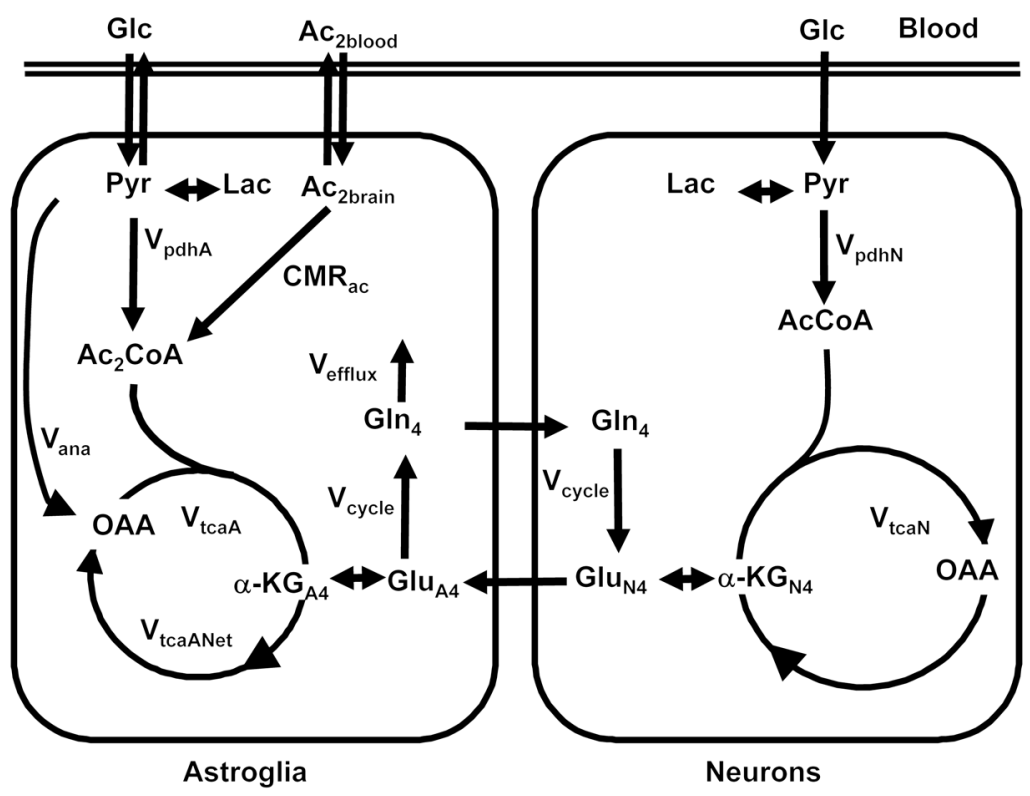

Figure 4

Metabolic pathways showing brain uptake of $\left[2-{ }^{13} \mathrm{C}\right]$ acetate and transfer of the ${ }^{13} \mathrm{C}$ labeling to glutamine and glutamate in astroglia and neurons. Astroglia consume acetate, while neurons and astroglia both consume glucose (Glc). The acetate labeled at the methyl group, whose carbon is designated $2\left(\mathrm{Ac}_{2}\right)$, enters the astroglia and the TCA cycle to form C2-labeled acetyl $\mathrm{CoA}\left(\mathrm{Ac}_{2} \mathrm{CoA}\right)$. In the first turn of the Krebs cycle, it labels the $\mathrm{C} 4$ of astroglial $\alpha$-ketoglutarate $\left(\alpha-\mathrm{KG}_{\mathrm{A} 4}\right)$, which exchanges to form glutamate $\mathrm{C} 4\left(\mathrm{Glu} \mathrm{u}_{\mathrm{A}}\right)$. Astroglia convert glutamate to glutamine, forming glutamine C4 $\left(G \mid n_{4}\right)$, which is transferred to neurons, converted, and mixed with the large neuronal pool of glutamate (Glu $\left.u_{N 4}\right)$. Some of the glutamate is released as part of glutamate-glutamine cycling, and some exchanges to form neuronal $\alpha$-ketoglutarate $\left(\alpha-K_{\mathrm{N}}\right)$. In both compartments, the carbon continues through the cycle and labels oxaloacetate (OAA) and labels glutamate and glutamine at C3 (data not shown) but does not return to the $\mathrm{C} 4$ of glutamate and glutamine. Meanwhile, the vast majority of glucose remains unlabeled and dilutes the pool of acetyl CoA and the Krebs cycle intermediates in neurons and astroglia. AcCoA, acetyl-CoA; Lac, lactate; Pyr, pyruvate.

\section{Discussion}

In this study, we have shown that chronic heavy drinking increases brain acetate utilization and blood-brain transport of acetate. In the presence of similar levels of plasma acetate, heavy drinkers were able to use more acetate as an alternative energy fuel to support brain metabolism. Acetate could potentially promote continued heavy drinking with a reward in the form of caloric benefit or adenosinergic adaptation.

Glutamate-glutamine cycling and GABA synthesis. A finding of potential clinical significance was the increased ratio of glutamate-glutamine cycling $\left(V_{c y c l e}\right)$ relative to the neuronal TCA cycle rate $\left(V_{t c a N}\right)$ in heavy drinkers, although in this nondependent group, the finding was unexpected. The change could occur if $V_{c y c l e}$ was greater or if $V_{t c a N}$ was lower or some combination of both. For the case of elevated $V_{c y c l e}$, one possibility is advanced liver disease, in which hepatic encephalopathy could increase conversion of glutamate to glutamine (35), but these subjects had normal liver function tests. Another explanation for elevated $V_{\text {cycle }}$ is that after at least 2 days without alcohol, there was increased glutamatergic tone that stimulated greater astroglial uptake and conversion to glutamine. Yet another possibility is that the $V_{c y c l e} / V_{t c a N}$ ratio was higher due to a slower $V_{\text {tcaN }}$. Most brain energy consumption is neuronal (36) and supplied by glucose. Brain glucose uptake has been reported to be $12 \%$ lower in the occipital cortex in recently abstinent alcohol-dependent subjects (37) or not different (38), so one expects at most a $12 \%$ reduction in $V_{t c a N}$ and therefore little impact on the estimated values of $V_{\text {cycle }}$ and $\mathrm{CMR}_{\mathrm{ac}}$, compared with the differences between the groups. Of note is the recently proposed theory that the ratio of glutamine/glutamate concentrations might reflect glutamateglutamine cycling (39), but in this case, $V_{\text {cycle }}$ differed without differences in the overall $\left({ }^{12} \mathrm{C}+{ }^{13} \mathrm{C}\right)$ levels of glutamate and glutamine. A finding that is potentially related to the increased rate $V_{c y}$. cle was that ${ }^{13} \mathrm{C}$ GABA was detected in heavy drinkers but not in light drinkers. In this study, if the light drinkers consumed half as much acetate as the heavy drinkers, then the light drinkers would be expected to have a concentration of ${ }^{13} \mathrm{C}-\mathrm{GABA}$ equal to $0.045 \mathrm{mmol} / \mathrm{kg}$, which is right at the lowest reasonable limit of detection given the spectral noise. Therefore, although it is possible that ${ }^{13} \mathrm{C}$-GABA was increased by higher glutamate-glutamine cycling, we cannot differentiate between that possibility and simple detectability limits.

Increased availability of acetate for brain metabolism. Chronic heavy drinkers spend a large fraction of time with elevated blood acetate, and the greater brain acetate metabolism can potentially be induced by the habitual generation of acetic acid in the blood from alcohol, as observed previously in humans and other animals $(40,41)$ Furthermore, chronic heavy drinking without eating can induce episodes of hypoglycemia (42), which have been shown to increase blood-brain monocarboxylic acid transport and therefore increase brain availability of acetate (28). In the present case, the baseline levels of plasma acetate in heavy drinkers were more than twice those in the light drinkers, despite the study-required 48-hour abstinence from alcohol. The levels of brain acetate in light and heavy drinkers, respectively, were $0.039 \mathrm{mmol} / \mathrm{kg}$ and 

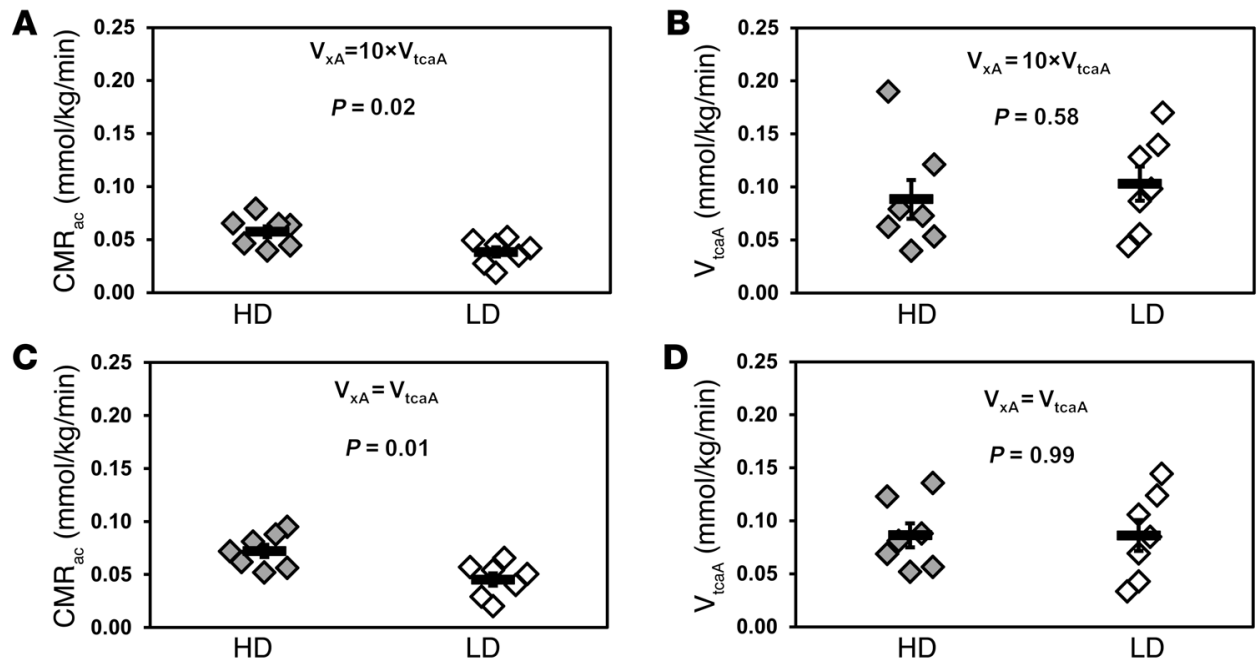

\section{Figure 5}

Metabolic rates calculated based on individual ${ }^{13} \mathrm{C}$ time courses of Glu4 and Gln4 and the steady state of Glu3 and Gln3. The value of $V_{x A}$, which is the rate of exchange between astroglial $\alpha$-ketoglutarate and glutamate, has not been determined. The kinetics was therefore tested over a range of values of $V_{x A}$. Its minimum possible value is equal to the rate of the TCA cycle $V_{\text {tcaA }}$, and, for values above $10 \times V_{\text {tcaA }}$, there is negligible difference in the kinetic impact compared with infinity (70), so $V_{x A}=10 \times V_{\text {tcaA }}$ was selected as the maximum of the range. (A) $C M R_{a c}$ was calculated assuming $V_{x A}=10 \times V_{t c a A}$. CMR $\mathrm{R}_{\mathrm{ac}}$ was significantly greater in the heavy drinking group $(P=0.02)$. (B) Astroglial TCA cycle $\left(V_{t c a A}\right)$ rates did not differ $(P=0.58)$ when $V_{x A}=10 \times V_{t c a A}$. (C) $C M R_{a c}$ was calculated assuming $V_{x A}=V_{t c a A}$, showing significant differences between heavy drinkers and light drinkers $(P=0.01)$. (D) $V_{\text {tcaA }}$ showed no difference between heavy drinker and light drinker groups when $V_{x A}=V_{\text {tcaA }}(P=0.99)$. Values with error bars represent group mean \pm SEM. Symbols represent individual concentrations; horizontal bars indicate the mean.

$0.071 \mathrm{mmol} / \mathrm{kg}$ (Figure 6). Given an acetate distribution space of $0.32 \mathrm{ml} / \mathrm{g}(43)$, the respective acetate concentrations in solution were $0.12-0.22 \mathrm{mM}$, close enough to the $K_{\mathrm{M}}$ of $0.17 \mathrm{mM}$ for utilization (43). There must have been a nearly exclusive unidirectional inflow of acetate from blood to brain, and the increased transport could double the rate of oxidation. It is therefore possible that the elevation of brain acetate via transport is sufficient to drive its oxidation. Possible impacts on transport were slightly higher levels of $\beta$-hydroxybutyrate in heavy drinkers, although that would compete with acetate for transport, so any increased transport in heavy drinkers is large enough to overcome whatever differences in ketone bodies might exist. The 10\%-20\% lower levels of lactate in the drinkers would be expected to increase acetate trans- port slightly through reduced competition for transport but not enough to explain the much greater metabolism seen here. Such impact of transport, facilitating some conversion from glucose to acetate consumption, would be consistent with recent data that show that the rat brain decreases uptake and phosphorylation of glucose when the acetate levels are higher in the blood (31). Human results also show decreased glucose uptake and higher acetate consumption in the presence of alcohol (30). An important but challenging measurement to make in these populations would be blood-brain transport of acetate.

Potential energetic impact of acetate in heavy drinking. Although in this study we recruited only healthy subjects that had no significant health issues related to heavy drinking, and the acetate
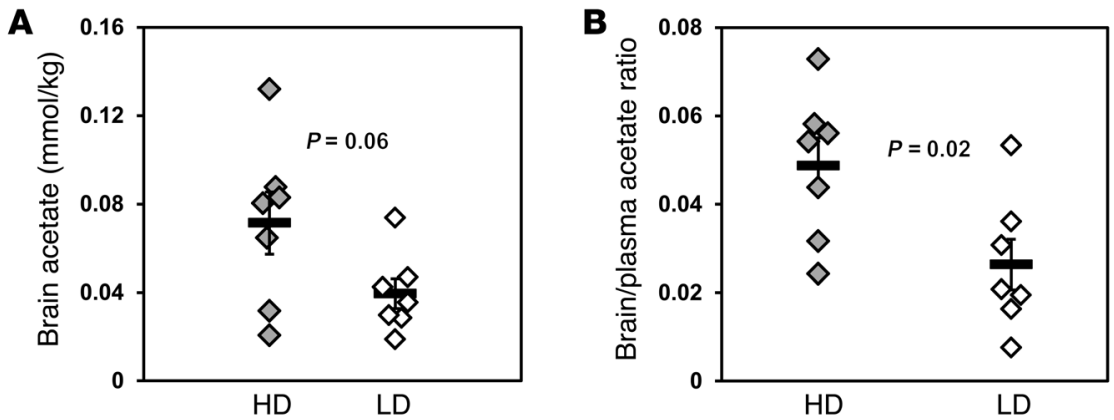

Figure 6

Brain acetate concentrations during steady-state $\left[2-{ }^{13} \mathrm{C}\right]$ acetate infusion, showing heavy drinkers have increased $\left[2-{ }^{13} \mathrm{C}\right] \mathrm{Ccetate}$ in brain. (A) Steady-state brain $\left[2-{ }^{13} \mathrm{C}\right]$ acetate concentrations during the $\left[2-{ }^{13} \mathrm{C}\right]$ acetate infusion. (B) Ratios of brain/blood acetate concentrations at steady-state $\left[2-{ }^{13} \mathrm{C}\right]$ acetate infusion. Values with error bars represent group average \pm SEM. Symbols represent individual concentrations; horizontal bars indicate the mean. 

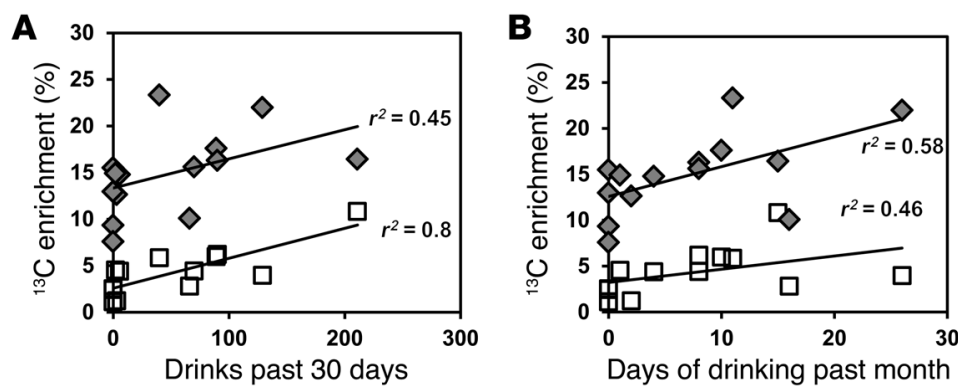

Figure 7

Correlations between glutamate $\mathrm{C} 4$ and glutamine $\mathrm{C} 4$ enrichments and recent drinking history for both heavy drinkers and light drinkers. (A) Correlation with drinks in the past 30 days for Glu4 $(P=0.0005)$ and Gln4 $(P=0.1)$. (B) Correlation with days of drinking in the past month for Glu4 $(P=0.098)$ and Gln4 $(P=0.03)$. Gray diamonds represent $\mathrm{Gln} 4{ }^{13} \mathrm{C}$ enrichments, and white squares represent $\mathrm{Glu} 4{ }^{13} \mathrm{C}$ enrichments.

infusions were performed under euglycemia, acetate metabolism in heavy drinkers showed a profile that was similar to what has been seen in patients with type 1 diabetes who have experienced antecedent recurrent hypoglycemia (28). Heavy drinking promotes a wide range of health problems related to hypoglycemia, such as impairment of gluconeogenesis, malnutrition, and confounding conditions like diabetes (44). Binge drinking itself decreases levels of NADH, thereby decreasing pyruvate levels and reducing gluconeogenesis (45). Compounding hypoglycemic conditions, there is evidence that some alcoholics have depressed counterregulatory responses to hypoglycemia (46). Alcohol caused a small reduction in plasma glucose concentration, from 5.1 to $4.7 \mathrm{mM}$, when infused to achieve a blood alcohol level of $60 \mathrm{mg} \%$ (47), which demonstrates that even without causing full-blown episodes of hypoglycemia, alcohol has the capacity to reduce levels of glucose, which is the brain's primary energy supply. In fact, the largest triggers of alcohol-induced hypoglycemia appear to be binge drinking and failure to eat. Although few heavy drinkers experience hypoglycemia at any given moment (48), our results in patients with type 1 diabetes show that intermittent hypoglycemia is sufficient to double acetate transport and consumption (28). Therefore, the adaptation of monocarboxylic acid transport and metabolism seen in heavy drinkers may reflect adaptations similar to those seen in type 1 diabetes with antecedent recurrent hypoglycemia.

Because acetate is consumed exclusively in astroglia (49), such an energy supplement is expected to have its primary impact on glia. When glucose is in short supply, elevated acetate consumption can potentially support a large fraction of astrocytic energy needs and leave more glucose available to supply neurons (27). In this study's population, no additional energy was needed for brain function in heavy drinkers, as evidenced by the fact that $V_{t c a A}$ was constant between heavy drinkers and light drinkers and that the increase in $\mathrm{CMR}_{\mathrm{ac}}$ in heavy drinkers was accompanied by decreased $V_{p d h A}$, as predicted by the observations of Pawlosky and colleagues (31). However, in an abusing or dependent population that is malnourished, the additional fuel could provide some reward in the form of energetic benefit. Given the ability of ethanol to cause acute drops in blood glucose $(26,45,47)$, the acetate formed from ethanol has the potential to provide a compensatory reward in the form of calories, thereby encouraging continued drinking.

Potential for adenosinergic impact of acetate consumption. Intracellular adenosine is produced by dephosphorylation of AMP (50) and other chemicals, including cAMP, ADP, and ATP (51), that involve signal transduction and metabolism sensing. Oxidation of acetate generates adenosine (52), and ethanol itself raises extracellular adenosine (42), which is sedating, with properties similar to those of alcohol intoxication $(45,46)$. The ethanol-based elevation of blood acetate persists for up to 24 hours (53), so heavy drinkers are exposed to high levels of acetate for sustained periods of time. It was not feasible with MRS to measure extracellular adenosine, but the elevated acetate oxidation suggests that adenosinergic effects from ethanol-derived acetate are likely to be enhanced in heavy drinkers. Persistent elevation of intracerebral adenosine has the potential to induce adenosinergic adaptations that contribute to continue heavy drinking. As drinkers become accustomed to chronic elevations of adenosine, drinking cessation may lead to discomfort with the decreased adenosine, and restoration of the adenosine by heavy drinking could be rewarding $(20,54)$.

Pitfalls and limitations. Although patients were instructed not to drink alcohol for 48 hours before the study, they could only be tested with a breathalyzer the morning of the measurement, which showed a value of 0 in every case. If someone drank less than 48 hours before the study, they could have cleared the alcohol but still have elevated acetate. That might explain the elevated levels of blood acetate before infusion, but during the infusion the acetate levels did not differ between the groups. A potential limitation is the apparent complexity of the metabolic model, given the small population of subjects. However, although this model contains many elements, it is subject to mass balance constraints that greatly reduce the number of free parameters and follows the generally accepted scenario of astroglial oxidation of acetate and glutamate-glutamine neurotransmitter cycling and has been applied in animals and humans in a variety of metabolic conditions (25, 55-58). If ${ }^{13} \mathrm{C}$-glucose infusions were performed to boost the sensitivity of the measurements to the value of the neuronal TCA cycle rate, that would decrease the number of assumptions to be made.

Conclusions. In summary, we have identified cerebral metabolic changes that are associated with heavy drinking. The changes suggest that chronic heavy drinking can induce upregulation of bloodbrain monocarboxylate transport and increase the capacity of the brain to oxidize acetate. The results of increased ethanol-derived acetate consumption have the potential to increase extracellular adenosine levels, thereby adding an adenosinergic effect to the potential caloric benefit that acetate provides with continued heavy drinking. Our findings in heavy drinkers provide potentially useful information in treatment of alcohol-dependent subjects by suggesting the provision of acetate and/or adenosinergic support during detoxification to alleviate withdrawal symptoms. 


\section{Methods}

Subjects. Healthy subjects, age 21-46, without alcohol dependence were recruited from the community via local advertisement. Heavy drinkers and light drinkers were age $29.7 \pm 9.6$ and $28.6 \pm 7.7$ years, respectively $(P=0.81)$. Pregnant women (evaluated by urine pregnancy tests) and people with a history of neurological disorders or contraindications for MRI were excluded. Individuals were also excluded on the basis of a structured diagnostic interview (SCID-II) that revealed a psychoactive substance abuse history other than tobacco smoking or heavy drinking in the previous 6 months (59). Other exclusion criteria included a lifetime history of posttraumatic stress disorder, bipolar disorder, or schizophrenia in self or first-degree family members and unwillingness to remain alcohol-free for the 48 hours before test days. Men who drank more than 14 drinks per week or women who drank more than 8 drinks per week were recruited as heavy drinkers, and people who drank fewer than 2 drinks per week were recruited as light drinkers. Alcohol consumption in the month prior to the testing date was determined using the timeline follow-back method (60). Subjects were asked to refrain from alcohol for 48 hours and fast for 10 hours before the acetate infusion in order to minimize the acute effect of ethanol and glucose on acetate metabolism. We enrolled 8 heavy drinkers ( 2 female, 6 male) and 8 light drinkers ( 2 female, 6 male). For the metabolic kinetic analysis, 1 light drinker was excluded due to extreme exercise and diet conditions, which have the potential to alter monocarboxylic acid transport and metabolism $(61,62)$, and 1 heavy drinker was excluded due to elevated ${ }^{13} \mathrm{C}$ enrichment of $\beta$-hydroxybutyrate in the blood. For purposes of screening and acclimation to the scanner environment before undergoing the acetate infusion, we offered to perform a ${ }^{1} \mathrm{H}$ MRS scan on subjects before the infusion day. Five out of seven heavy drinkers and six out of seven light drinkers included in the study underwent ${ }^{1} \mathrm{H}$ MRS.

${ }^{1} \mathrm{H}$ MRS. ${ }^{1} \mathrm{H}$ MRS studies were performed with a $4 \mathrm{~T}$ magnet (Oxford Magnetic Technology) and a Bruker spectrometer (Bruker Instruments), as described previously (63). The head of the subject was comfortably secured to a platform with the region of interest apposed to an 8-cm distributed capacitance surface coil tuned to $170 \mathrm{MHz}$. A $\mathrm{T}_{1}$-weighted multislice MRI was obtained for anatomical localization. From the image, a $3 \times 1.5 \times 3-\mathrm{cm}$ region of interest was selected, centered on the midline of the occipital cortex, within the volume of the larger ${ }^{13} \mathrm{C}$ MRS voxel. Automated first- and second-order shimming was applied in the volume of interest (64). GABA was acquired over 20 minutes using a J-editing pulse sequence (65), as this provides a very sensitive test and training for the subject to hold sufficiently still for MRS. The spectral acquisition parameters were as follows: repetition time, 2.5 seconds; echo time, 68 milliseconds; sweep width, 15,000 Hz; and acquisition time, 510 milliseconds. An unsuppressed, localized spectrum of water was acquired for use as an internal concentration standard. The acquisition procedure, with setup, lasted approximately 45 minutes. In addition to GABA, glutamate, glutamine, NAA, and other metabolites were detected and fitted in the spectral domain with a measured basis set of metabolites. The free-induction decays were zero filled to $32 \mathrm{~K}$, processed with $-2 \mathrm{~Hz}$ Lorentzian $/ 6 \mathrm{~Hz}$ Gaussian broadening, and Fourier transformed. The results of these measurements were used to assess whether NAA, glutamate, and glutamine differed between these heavy drinkers and light drinkers.

$\left[2-{ }^{13} \mathrm{C}\right]$ acetate infusion. On the day of the study, breath alcohol was verified to be 0 using an Alcotest 6810 breathalyzer (Draeger Inc.). An intravenous catheter was placed in the antecubital vein of each arm, one to infuse ${ }^{13} \mathrm{C}$-acetate and the other to draw blood samples. Venous blood samples were obtained every 10 minutes, starting 20 minutes before the infusion, and continued throughout the infusion. The infusate, $350 \mathrm{mM}\left[2-{ }^{13} \mathrm{C}\right]$ acetate (99\% enriched; Isotec), was prepared by the Investigational Drug Service at Yale-New Haven Hospital. The acetate infusion was carried out at a rate of $6 \mathrm{mg} / \mathrm{kg} / \mathrm{min}$ for the first 5 minutes, followed by a continuous infusion of $3 \mathrm{mg} / \mathrm{kg} / \mathrm{min}$ for approximately 115 minutes (28).
${ }^{13} \mathrm{C}$ MRS. MRS data were acquired on a 4 Tesla whole-body magnet connected to an imaging spectrometer (Bruker Instruments), as described previously (66). Subjects lay supine in the magnet, with the head lying on top of a radiofrequency magnetic resonance probe consisting of one 8.5-cm diameter circular ${ }^{13} \mathrm{C}$-coil and $2{ }^{1} \mathrm{H}$ quadrature coils for acquisition and decoupling (67). After tuning and acquisition of scout images, a voxel of $5 \times 4 \times 4.5 \mathrm{~cm}^{3}$ was selected in the occipital-parietal region. Shimming was performed using FASTERMAP (68). ${ }^{13} \mathrm{C}$-MR spectra were acquired using an adiabatic ${ }^{13} \mathrm{C}-\left[{ }^{1} \mathrm{H}\right]$ polarization transfer sequence optimized for the detection of glutamate and glutamine $\mathrm{C} 4$, with ISIS localization, acquiring 765 complex points with a $5,000 \mathrm{~Hz}$ bandwidth and a repetition time of 2.5 seconds. Free-induction decays were averaged in groups of 128 to yield 5.3-minute blocks. After 1 baseline block, ${ }^{13} \mathrm{C}$-MRS spectra were acquired continuously throughout the infusion with the 5.3-minute blocks for 2 hours.

The spectral data were prepared for analysis with $-2 \mathrm{~Hz} / 6 \mathrm{~Hz}$ Lorentzian-to-Gaussian conversion and 16 -fold zero filling, followed by Fourier transformation. An in-house LC model-type approach was used to fit peak areas of ${ }^{13} \mathrm{C}$-labeled glutamate $\mathrm{C} 4$ and $\mathrm{C} 3$, glutamine $\mathrm{C} 4$ and $\mathrm{C} 3$, GABA C2 and C3, and NAA C3 and C6. A Monte-Carlo analysis was used to estimate the standard deviations of each metabolite's labeling from the fitting program (69). Because NAA C3 and C6 were not enriched measurably by the 2-hour acetate infusion, the natural ${ }^{13} \mathrm{C}$ abundance of NAA signals of NAA C 3 and C6 were averaged over the duration of the study and used as an internal standard to estimate the ${ }^{13} \mathrm{C}$-labeled concentrations of glutamate and glutamine. For steady-state brain ${ }^{13} \mathrm{C}$-acetate concentrations, we were reporting the summation of the last 5 FIDs.

Plasma acetate concentrations and ${ }^{13} \mathrm{C}$ enrichments were measured in samples using water-suppressed ${ }^{1} \mathrm{H}$-observed $/{ }^{13} \mathrm{C}$-edited NMR spectroscopy on $11.7 \mathrm{~T}$ Bruker AVANCE high-resolution NMR spectrometer by mixing $50 \mu \mathrm{l}$ plasma with $50 \mu \mathrm{l} 2.5 \mathrm{mM}$ formic acid in $100 \mathrm{mM}$ phosphate buffer ( $\mathrm{pH} 7.4$ ) and $40 \% \mathrm{D}_{2} \mathrm{O}$.

Metabolic modeling analysis. Metabolic rates were determined by fitting a 2-compartment model of astroglia and neuronal metabolism, using the time courses of ${ }^{13} \mathrm{C}$ enrichment of glutamate and glutamine $\mathrm{C} 4$ and the steadystate enrichments of glutamate and glutamine $\mathrm{C} 3$. The time courses of plasma acetate ${ }^{13} \mathrm{C}$ enrichments were used as inputs for the modeling analysis. Because the blood-brain transport kinetics for acetate in humans has not been measured, the modeling does not include kinetic parameters for transport through the $\mathrm{BBB}$ or for acetate utilization. Therefore, $\mathrm{CMR}_{\mathrm{ac}}$ reflects both transport and utilization. However, because plasma acetate levels were similar in both groups, any observed differences in acetate metabolism reflect actual changes in kinetic parameters for acetate transport and/or utilization, rather than changes in acetate uptake due solely to changes in plasma acetate concentration. Mass and isotopic flows from $\left[2-{ }^{13} \mathrm{C}\right]$ acetate to brain glutamate and glutamine were expressed as coupled differential equations with CWave 3.0 (33) running in Matlab (Mathworks). The equations (Table 1) were solved using a first-order Runge-Kutta algorithm, and least-squares optimization was achieved using a Levenberg-Marquardt algorithm.

Statistics. Repeated-measures multivariate ANOVA was used to compare the time courses of ${ }^{13} \mathrm{C}$ labeling of glutamate and glutamine, with posthoc pairwise testing performed to assess differences between groups. A 2 -sample $t$ test was performed to assess differences in initial plasma acetate, steady-state brain acetate, and $\mathrm{CMR}_{\mathrm{ac}}$ between the heavy drinkers and light drinkers. A 2-tailed $P$ value of $<0.05$ was considered statistically significant. All data are presented as mean \pm SEM. ANOVA was used to compare the enrichments of glutamate $\mathrm{C} 4$, glutamine $\mathrm{C} 4$, and GABA C2 between the heavy drinkers and light drinkers. Post-hoc $t$ tests for independent samples were performed to assess which measurements differed significantly between the groups. 
Study approval. This project was approved by the Yale University Human Research Protection Program. Before participation, all subjects provided written informed consent.

\section{Acknowledgments}

This publication was made possible by NIH grants R21 AA018210 (to G.F. Mason), R21 AA019803 (to G.F. Mason), R01 DA021785 (to G.F. Mason), and CTSA grant UL1 RR024139 from the National Center for Research Resources and the National Center for Advancing Translational Science, components of the NIH, and NIH Road- map for Medical Research. Its contents are solely the responsibility of the authors and do not necessarily represent the official view of NIH.

Received for publication June 1, 2012, and accepted in revised form January 17, 2013.

Address correspondence to: Lihong Jiang, N-147 TAC-MRRC, Yale University School of Medicine, 300 Cedar Street, PO Box 208043, New Haven, Connecticut 06520, USA. Phone: 203.785.2953; Fax: 203.785.6643; E-mail: lihong.jiang@yale.edu.
1. Prosser RA, Mangrum CA, Glass JD. Acute ethanol modulates glutamatergic and serotonergic phase shifts of the mouse circadian clock in vitro. Neuroscience. 2008;152(3):837-848.

2. Wallner M, Hanchar HJ, Olsen RW. Low-dose alcohol actions on alpha4beta3delta GABAA receptors are reversed by the behavioral alcohol antagonist Ro15-4513. Proc Natl Acad Sci U S A. 2006;103(22):8540-8545.

3. Wakita M, Shin MC, Iwata S, Nonaka K, Akaike N. Effects of ethanol on GABAA receptors in GABAergic and glutamatergic presynaptic nerve terminals. J Pharmacol Exp Ther. 2012;341(3):809-819.

4. Ting JW, Lautt WW. The effect of acute, chronic, and prenatal ethanol exposure on insulin sensitivity. Pharmacol Ther. 2006;111(2):346-373.

5. Manzo-Avalos S, Saavedra-Molina A. Cellular and mitochondrial effects of alcohol consumption. Int J Environ Res Public Health. 2010;7(12):4281-4304.

6. Lundquist F, Winkler K, Munckpet S, Tygstrup N, Mellemgaard K. Ethanol metabolism and production of free acetate in the human liver. J Clin Invest. 1962;41:955-961

7. Norberg A, Jones AW, Hahn RG, Gabrielsson JL. Role of variability in explaining ethanol pharmacokinetics - Research and forensic applications. Clinical Pharmacokinetics. 2003;42(1):1-31.

8. Jucker BM, Lee JY, Shulman RG. In vivo C-13 NMR measurements of hepatocellular tricarboxylic acid cycle flux. J Biol Chem. 1998; 273(20):12187-12194.

9. Lundquist F, Sestoft L, Damgaard SE, Clausen JP, Trap-Jensen J. Utilization of acetate in the human forearm during exercise after ethanol ingestion. J Clin Invest. 1973;52(12):3231-3235.

10. Davin A, Vion-Dury J, Viout P, Cozzone PJ. Rapid evaluation of ethanol content and metabolism in human plasma using quantitative proton magnetic resonance spectroscopy. Alcohol Alcohol. 1994;29(5):479-483.

11. Peng G-S, Chen Y-C, Tsao T-P, Wang M-F, Yin S-J. Pharmacokinetic and pharmacodynamic basis for partial protection against alcoholism in Asians, heterozygous for the variant ALDH $2 * 2$ gene allele. Pharmacogenet Genomics. 2007;17(10):845-855.

12. Nuutinen H, Lindros K, Hekali P, Salaspuro M. Elevated blood acetate as indicator of fast ethanol elimination in chronic alcoholics. Alcohol. 1985;2(4):623-626.

13. Mascord D, Smith J, Starmer GA, Whitfield JB. Effects of increasing the rate of alcohol metabolism on plasma acetate concentration. Alcohol Alco hol. 1992;27(1):25-28.

14. Patel AB, de Graaf RA, Rothman DL, Behar KL, Mason GF. Evaluation of cerebral acetate transport and metabolic rates in the rat brain in vivo using 1H-[13C]-NMR. J Cereb Blood Flow Metab. 2010;30(6):1200-1213.

15. Hellman L, Rosenfeld RS, Gallagher TF. Cholesterol synthesis from C-14-acetate in man. J Clin Invest. 1954;33(2):142-149.

16. Natali F, Siculella L, Salvati S, Gnoni GV. Oleic acid is a potent inhibitor of fatty acid and cholesterol synthesis in C6 glioma cells. J Lipid Res.
2007;48(9):1966-1975.

17. Pronko PS, Velichko MG, Moroz AR, Rubanovich NN. Low-molecular-weight metabolites relevant to ethanol metabolism: correlation with alcohol withdrawal severity and utility for identification of alcoholics. Alcohol Alcohol. 1997;32(6):761-768.

18. Kiviluoma KT, Peuhkurinen KJ, Hassinen IE. Adenine nucleotide transport and adenosine production in isolated rat heart mitochondria during acetate metabolism. Biochim Biophys Acta. 1989;974(3):274-281.

19. Kiselevski Y, et al. Acetate metabolism in brain mechanisms of adaptation to ethanol. Med Sci Monit. 2003;9(5):178-182.

20. Mailliard WS, Diamond I. Recent advances in the neurobiology of alcoholism: the role of adenosine. Pharmacol Ther. 2004;101(1):39-46.

21. Diamond I, Nagy L, Mochly-Rosen D, Gordon A. The role of adenosine and adenosine transport in ethanol-induced cellular tolerance and dependence. Possible biologic and genetic markers of alcoholism. Ann N Y Acad Sci. 1991;625:473-487.

22. Carmichael FJ, et al. Central nervous system effects of acetate: Contribution to the central effects of ethanol. J Pharmacol Exp Ther. 1991;259(1):403-408.

23. Carmichael FJ, Orrego H, Saldivia V, Israel Y. Effect of propylthiouracil on the ethanol-induced increase in liver oxygen consumption in awake rats. Hepatology. 1993;18(2):415-421.

24. Carmichael FJ, Orrego H, Israel Y. Acetate-induced adenosine mediated effects of ethanol. Alcohol Alcobol Suppl. 1993;2:411-418.

25. Muir D, Berl S, Clarke DD. Acetate and fluoroacetate as possible markers for glial metabolism in vivo. Brain Res. 1986;380(2):336-340.

26. Jain H, Beriwal S, Singh S. Alcohol induced ketoacidosis, severe hypoglycemia and irreversible encephalopathy. Med Sci Monit. 2002;8(11):CS77-CS79.

27. Jiang L, et al. Recurrent antecedent hypoglycemia alters neuronal oxidative metabolism in vivo. Diabetes. 2009;58(6):1266-1274.

28. Mason GF, Petersen KF, Lebon V, Rothman DL, Shulman GI. Increased brain monocarboxylic acid transport and utilization in type 1 diabetes. Diabetes. 2006;55(4):929-934.

29. Volkow ND, et al. Low doses of alcohol substantially decrease glucose metabolism in the human brain. Neuroimage. 2006;29(1):295-301.

30. Volkow ND, et al. Acute alcohol intoxication decreases glucose metabolism but increases acetate uptake in the human brain. Neuroimage. 2013;64:277-283.

31. Pawlosky RJ, et al. Alterations in brain glucose utilization accompanying elevations in blood ethanol and acetate concentrations in the rat. Alcohol Clin Exp Res. 2010;34(2):375-381.

32. Sarkola T, Iles MR, Kohlenberg-Mueller K, Eriksson CJ. Ethanol, acetaldehyde, acetate, and lactate levels after alcohol intake in white men and women: effect of 4-methylpyrazole. Alcohol Clin Exp Res. 2002;26(2):239-245.

33. Clubb R, Mason G. Animal welfare: captivity effects on wide-ranging carnivores. Nature. 2003;425(6957):473-474.
34. Lebon V, et al. Astroglial contribution to brain energy metabolism in humans revealed by $13 \mathrm{C}$ nuclear magnetic resonance spectroscopy: elucidation of the dominant pathway for neurotransmitter glutamate repletion and measurement of astrocytic oxidative metabolism. J Neurosci. 2002;22(5):1523-1531.

35. Brusilow SW, Koehler RC, Traystman RJ, Cooper AJL. Astrocyte glutamine synthetase: importance in hyperammonemic syndromes and potential target for therapy. Neurotherapentics. 2010;7(4):452-470.

36. Shulman RG, Rothman DL, Behar KL, Hyder F. Energetic basis of brain activity: implications for neuroimaging. Trends Neurosci. 2004;27(8):489-495.

37. Volkow N, et al. Decreased brain metabolism in neurologically intact healthy alcoholics. Am J Psychiatry. 1992;149(8):1016-1022.

38. Hommer D, et al. Effects of m-chlorophenylpiperazine on regional brain glucose utilization: a positron emission tomographic comparison of alcoholic and control subjects. J Neurosci. 1997; 17(8):2796-2806.

39. Theberge J, et al. Glutamate and glutamine measured with $4.0 \mathrm{~T}$ proton MRS in never-treated patients with schizophrenia and healthy volunteers. Am J Psychiatry. 2002;159(11):1944-1946.

40. Korri UM, Nuutinen H, Salaspuro M. Increased blood acetate: a new laboratory marker of alcoholism and heavy drinking. Alcohol Clin Exp Res. 1985;9(5):468-471.

41. McBride WJ, Li TK. Animal models of alcoholism: neurobiology of high alcohol-drinking behavior in rodents. Crit Rev Neurobiol. 1998;12(4):339-369.

42. Marks V. Clinical pathology of alcohol. J Clin Pathol. 1983;36(4):365-378.

43. Patel AB, De Graaf RA, Rothman DL, Behar KL, Mason GF. Evaluation of cerebral acetate transport and metabolic rates in the rat brain in vivo using (1)H- (13)C -NMR. J Cereb Blood Flow Metab. 2010;30(6):1200-1213.

44. Brecher AS, Lehti MD. A hypothesis linking hypoglycemia, hyperuricemia, lactic acidemia, and reduced gluconeogenesis in alcoholics to inactivation of glucose-6-phosphatase activity by acetaldehyde. Alcohol. 1996;13(6):553-557.

45. Krebs HA, Freedland RA, Hems R, Stubbs M. Inhibition of hepatic gluconeogenesis by ethanol. Biochem J. 1969;112(1):117-124.

46. Wright J. Endocrine effects of alcohol. Clin Endocrinol Metab. 1978;7(2):351-367.

47. Juhlin-Dannfelt A. Ethanol effects of substrate utilization by the human brain. Scand J Clin Lab Invest. 1977;37(5):443-449.

48. Sporer KA, Ernst AA, Conte R, Nick TG. The incidence of ethanol-induced hypoglycemia. Am J Emerg Med. 1992;10(5):403-405

49. Waniewski RA, Martin DL. Astrocytes and synaptosomes transport and metabolize lactate and acetate differently. Neurochem Res. 2004;29(1):209-217.

50. Borowiec A, Lechward K, Tkacz-Stachowska K, Skladanowski AC. Adenosine as a metabolic regulator of tissue function: production of adenosine by cytoplasmic 5'-nucleotidases. Acta Biochim Pol. 2006;53(2):269-278. 
51. Dunwiddie TV, Diao L, Proctor WR. Adenine nucleotides undergo rapid, quantitative conversion to adenosine in the extracellular space in rat hippocampus. J Neurosci. 1997;17(20):7673-7682.

52. Kiviluoma KT, Peuhkurinen KJ, Hassinen IE. Adenine nucleotide transport and adenosine production in isolated rat heart mitochondria during acetate metabolism. Biochim Biophys Acta. 1989;974(3):274-281.

53. Verdy M, Saliou-Diallo G. [Hypoglycemia and alcohol]. Can Med Assoc J. 1968;98(17):827-830.

54. Asatryan L, et al. Implication of the purinergic system in alcohol use disorders. Alcohol Clin Exp Res. 2011;35(4):584-594.

55. Badar-Goffer RS, Bachelard HS, Morris PG. Cerebral metabolism of acetate and glucose studied by ${ }^{13} \mathrm{C}$-n.m.r. spectroscopy. A technique for investigating metabolic compartmentation in the brain. Biochem J. 1990;266(1):133-139.

56. Lebon $\mathrm{V}$, et al. Astroglial contribution to brain energy metabolism in humans revealed by ${ }^{13} \mathrm{C}$ nuclear magnetic resonance spectroscopy: elucidation of the dominant pathway for neurotransmitter glutamate repletion and measurement of astrocytic oxidative metabolism. I Neurosci. 2002;22(5):1523-1531.

57. van den Berg CJ, Garfinkel D. A stimulation study of brain compartments. Metabolism of glutamate and related substances in mouse brain. Biochem J. 1971;123(2):211-218

58. Patel AB, de Graaf RA, Mason GF, Rothman DL Shulman RG, Behar KL. The contribution of GABA to glutamate/glutamine cycling and energy metabolism in the rat cortex in vivo. Proc Natl Acad Sci US A. 2005;102(15):5588-5593.

59. Feinstein A, Stergiopoulos V, Fine J, Lang AE. Psychiatric outcome in patients with a psychogenic movement disorder: a prospective study. Neuropsychiatry Neuropsychol Behav Neurol. 2001;14(3):169-176.
60. Sobell LC, Sobell MB. Timeline follow-back: a technique for assessing self-reported alcohol consumption. In: Litten RZ, Allen JP, eds. Measuring Alcohol Consumption: Psychosocial And Biochemical Methods. Totowa, New Jersey, USA: Humana Press; 1993:41-72.

61. Coles L, Litt J, Hatta H, Bonen A. Exercise rapidly increases expression of the monocarboxylate transporters MCT1 and MCT4 in rat muscle. J Physiol. 2004;561(pt 1):253-261.

62. Leino RL, Gerhart DZ, Duelli R, Enerson BE, Drewes LR. Diet-induced ketosis increases monocarboxylate transporter (MCT1) levels in rat brain. Neurochem Int. 2001;38(6):519-527.

63. Morgan P, et al. Cortical GABA levels in primary insomnia. Sleep. 2012;35(6):807-814.

64 . Shen J, Rycyna RE, Rothman DL. Improvements on an in vivo automatic shimming method [FASTERMAP]. Magn Reson Med. 1997;38(5):834-839.

65. Rothman DL, Petroff OA, Behar KL, Mattson RH. Localized 1H NMR measurements of gamma-aminobutyric acid in human brain in vivo. Proc Natl Acad Sci U S A. 1993;90(12):5662-5666.

66. Boumezbeur F, et al. Altered brain mitochondrial metabolism in healthy aging as assessed by in vivo magnetic resonance spectroscopy. J Cereb Blood Flow Metab. 2010;30(1):211-221.

67. Shen J, et al. Determination of the rate of the glutamate/glutamine cycle in the human brain by in vivo 13C NMR. Proc Natl Acad Sci U S A. 1999 96(14):8235-8240.

68. Shen J, Rycyna RE, Rothman DL. Improvements on an in vivo automatic shimming method [FASTERMAP]. Magn Reson Med. 1997;38(5):834-839.

69. Valentine GW, et al. The antidepressant effect of ketamine is not associated with changes in occipital amino acid neurotransmitter content as measured by [(1)H]-MRS. Psychiatry Res. 2011;191(2):122-127.

70. Mason GF, Rothman DL, Behar KL, Shulman RG.
NMR determination of the TCA cycle rate and alpha-ketoglutarate/glutamate exchange rate in rat brain. J Cereb Blood Flow Metab. 1992;12(3):434-447.

71. Patel AB, de Graaf RA, Mason GF, Rothman DL, Shulman RG, Behar KL. The contribution of GABA to glutamate/glutamine cycling and energy metabolism in the rat cortex in vivo. Proc Natl Acad Sci U S A. 2005;102(15):5588-5593.

72. Gjedde A, Diemer NH. Autoradiographic determination of regional brain glucose content. J Cereb Blood Flow Metab. 1983;3(3):303-310.

73. Gruetter R, Ugurbil K, Seaquist ER. Steady-state cerebral glucose concentrations and transport in the human brain. J Neurochem. 1998;70(1):397-408.

74. Mason GF, Petersen KF, de Graaf RA, Shulman GI, Rothman DL. Measurements of the anaplerotic rate in the human cerebral cortex using $13 \mathrm{C}$ magnetic resonance spectroscopy and $[1-13 \mathrm{C}]$ and [2-13C] glucose. J Neurochem. 2007;100(1):73-86.

75. Mason GF, Gruetter R, Rothman DL, Behar KL, Shulman RG, Novotny EJ. Simultaneous determination of the rates of the TCA cycle, glucose utilization, alpha-ketoglutarate/glutamate exchange, and glutamine synthesis in human brain by NMR. J Cereb Blood Flow Metab. 1995;15(1):12-25.

76. Gruetter R, Seaquist ER, Ugurbil K. A mathematical model of compartmentalized neurotransmitter metabolism in the human brain. Am J Physiol Endocrinol Metab. 2001;281(1):E100-E112.

77. Gruetter R, et al. Localized 13C NMR spectroscopy in the human brain of amino acid labeling from D-[113C]glucose. J Neurochem. 1994;63(4):1377-1385.

78. Lebon V, et al. Astroglial contribution to brain energy metabolism in humans revealed by $13 \mathrm{C}$ nuclear magnetic resonance spectroscopy: elucidation of the dominant pathway for neurotransmitter glutamate repletion and measurement of astrocytic oxidative metabolism. J Neurosci. 2002;22(5):1523-1531. 